\title{
Preventing Pressure Sores in Hospital: Controlled Trial of a Large-celled Ripple Mattress
}

\author{
MARY R. BLISS,* M.B., B.S. ; RHODA MCLAREN,* R.G.N., S.C.M. ; A. N. EXTON-SMITH,† M.D., F.R.C.P.
}

Brit. med. F., 1967, 1, 394-397

An investigation of geriatric nursing problems in hospital carried out in 1959-60 has shown that the overall incidence of pressure sores in elderly patients is high (Norton et al., 1962). It was found that $12.5 \%$ of geriatric patients had pressure sores on admission to hospital and a further $22 \%$ subsequently developed them at some time during their stay. The average length of time the patients suffered from sores was three-fifths of their total length of stay and ranged from one day to more than six months. Contrary to popular opinion, they were not always a terminal event $(31 \%$ of these patients were eventually discharged), but even in those patients who died the average duration of the sores before death was 3.1 weeks. In a small work study conducted in the geriatric wards (to be published) the average nursing-time per patient was shown to be increased by $50 \%$ in patients with pressure sores compared with that of equally ill patients without sores. A large amount of this time was necessarily being devoted to the treatment rather than the prevention of sores.

The effective prevention of sores simply by intensive nursing care is almost impossible in wards with large numbers of susceptible patients and often with low ratios of nursing staff per patient. Moreover, patients apt to develop sores are to be found outside the geriatric department. In a single census carried out in May 1964 in the general medical, surgical, and orthopaedic wards of this hospital $40 \%$ of the patients were found to be over the age of 70 . With the increasing average age of Western populations the nursing care of the aged is making heavier demands on a profession which is experiencing growing difficulties in recruitment. Thus both for the patient and for the nurse the development of efficient aids, such as mechanical methods of preventing pressure sores, is important.

Innumerable remedies and machines for preventing pressure sores have been described and some of these have been reviewed (Bliss, 1964 ; Exton-Smith, 1966). Their ingenuity often suggests a great deal of enthusiasm (Hoffman et al., 1949 ; Blockey, 1953 ; Gardner et al., 1954 ; Ewing et al., 1961; Sandock, 1962), but apparently very few controlled trials have been attempted. This report deals with the results obtained from the use of a large-celled ripple mattress which was one of the methods assessed in a controlled trial during a period of two years involving 555 patients in three hospitals. A full account of the complete investigation has been published (Bliss et al., 1966).

\section{The Investigation}

The trial was concerned mainly with an assessment of different mattresses for preventing pressure sores, principally two alternating pressure mattresses-that is, the large- and small-celled ripple beds, the Sierex (air) mattress, a polyethylene foam mattress, the water bed, the natural sheepskin, and an acrylic fibre pad (North pad). The results of nursing patients on these mattresses were compared with those of control groups which included treatment by accepted techniques for preventing pressure sores-for example, regular turning-as well as ordinary ward care. Special attention was paid to the practic-

-Whittington Hospital, London N.19.

t Now Physician, University College Hospital, London. ability of the various methods tested for use in wards with low staff-patient ratios.

Large-celled Ripple Bed.-This bed was designed because experience with the small-celled ripple bed, the alternating pressure mattress commonly used in Great Britain, suggested that the narrow cells, 2 in. $(5 \mathrm{~cm}$.) wide in the deflated mattress, might be incapable of lifting a patient sufficiently clear of the mattress beneath to provide effective alternating pressure. The cells of the large-celled mattress used in these tests are 6 in. $(15 \mathrm{~cm}$.) wide, giving it a depth of $4 \mathrm{in}$. $(10 \mathrm{~cm}$.) when inflated (Fig. 1). Otherwise its design is similar in principle to the usual ripple bed. Both are $7 \mathrm{ft}$. $(2.1 \mathrm{~m}$.) long, capable of supporting a patient from the head to the heels, and consist of transverse air cells. In the large-celled mattress there are 14 cells, leaving a gap of $12 \mathrm{in}$. $(30 \mathrm{~cm}$.) to accommodate the pillow at the head of the bed. The cells are connected in two separate series-that is, if they are considered as being numbered 1 to 14 , one series consists of the even and the other of the odd numbers. Each of the two series is inflated and deflated by an electrically driven pump, so that the patient is supported on each series of cells in turn for about four to five minutes.

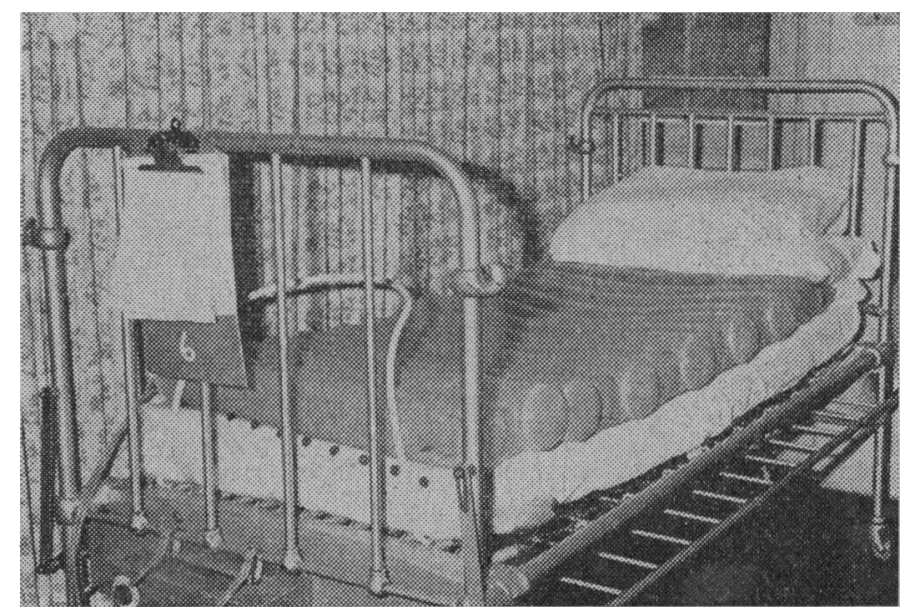

FIG. 1.-Large-celled ripple bed (cover removed).

Control.-Patients in the control group were nursed on ordinary hospital mattresses, but otherwise were selected and treated in exactly the same way as patients on the large-celled ripple bed.

\section{Method of Trial}

So far as possible, only patients liable to develop pressure sores were admitted to the trial. The selection of subjects was based on the use of a modified scoring system designed for previous studies in the geriatric department (Norton et al., 1962) (Table I). ${ }^{1}$ The patient was examined and a number given

: For convenience, the order of numbering has been reversed from that used in An Investigation of Geriatric Nursing Problems in Hospital. The positions of the grades "confused" and "apathetic" have also been interchanged 
corresponding to the most appropriate grade under each of the five headings $\mathrm{A}$ to $\mathrm{E}$. The numbers were then added together to give the "clinical score" for that particular examination. These scores, which ranged from 0 to 15 , had been shown to be associated with the development of pressure sores, patients with high scores being about four times as likely to develop pressure sores in the following two weeks as patients with low scores. In the case of inpatients the appearance of sores was more especially associated with a rising score. For the purpose of the trial all new patients entering the unit were scored on admission, and all inpatients at roughly four-day intervals. As a compromise between the desire not to admit to the trial too many patients who were not at risk, and not to miss patients who might subsequently have developed sores, a score of 7 was chosen as the dividing line. All new patients with a score of 7 or more, and all inpatients with a score of 7 or more and still rising, were admitted to the trial, provided they had no, or only superficial, trunk sores at the time. The presence of gangrenous heel sores did not prevent admission, but, as this was primarily a trial of methods of prophylaxis, no patients with severe sores of the trunk were accepted.

TABLE I.-Clinical Score

\begin{tabular}{|c|c|c|c|c|}
\hline $\begin{array}{c}\text { A. General } \\
\text { Condition }\end{array}$ & $\begin{array}{l}\text { B. Mental } \\
\text { State }\end{array}$ & C. Activity & $\begin{array}{l}\text { D. Mobility } \\
\text { in Bed }\end{array}$ & $\underset{\text { Incontinence }}{\mathrm{E}}$ \\
\hline $\begin{array}{l}0 \text { Good } \\
1 \text { Fair }\end{array}$ & $\begin{array}{l}0 \text { Alert } \\
1 \text { Confused }\end{array}$ & $\begin{array}{l}0 \text { Ambulant } \\
1 \text { Walks with }\end{array}$ & $\begin{array}{l}0 \text { Full } \\
1 \text { Slightly }\end{array}$ & $\begin{array}{l}0 \text { Not } \\
1 \text { Occasional }\end{array}$ \\
\hline 2 Poor & 2 Apathetic & 2 Chairfast & 2 Very ${ }_{\text {limited }}$ & 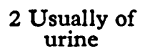 \\
\hline $3 \mathrm{Bad}$ & 3 Stuporous & $\begin{array}{l}3 \text { In bed all } \\
\text { day }\end{array}$ & 3 Immobile & $\begin{array}{l}3 \text { Doubly } \\
\text { incontinent }\end{array}$ \\
\hline
\end{tabular}

In order to ensure that the distribution of subjects among the various regimens was as random as possible the experimental and control treatments were arranged in a rota. As patients were admitted to the trial they were allocated to the next treatment on the rota in order.

Each patient was nursed in the trial for 14 days. An assessment of the clinical score and condition of the pressure areas was carried out every second day and recorded. During this time the general nursing care was standardized so far as was possible as follows: patients were nursed lying on their backs, as flat as possible, except during meals or when sitting out of bed ; they were not allowed up, if at all, for more than four hours daily; all patients had a bedcradle, but no massage or local treatment to the pressure areas beyond cleaning of incontinent petients, was allowed.

Follow-up assessments were carried out on the 16th day, two days after removal from the experimental mattress or regimen and return to normal ward care.

The record forms were all evaluated in a single session by one observer, each being masked in such a way that it was not possible to know to which patient or to which experimental regimen it referred. Two main types of pressure sore were considered: (1) trunk sores, including sores of the sacrum, buttocks, and hips, and (2) heel sores. Sores of the trunk were graded $0,+,++,+++,++++$ (full descriptions of these grades are given elsewhere-Bliss et al. (1966)). Grades + and ++ (Fig. 2) included sores which, however great their extent, were superficial ; grade +++ was used for situations in which there was some discoloration or oedema, indicating that deep damage was probably but not definitely present; grade +++ was reserved for full-thickness skin loss (gangrenous sores) (Fig. 3). Heel sores were graded similarly: + for superficial blisters or patches of faint discoloration only, and ++ and +++ for full-thickness gangrene.

Before discussing the results we feel we should make a few remarks about the general nursing care laid down for patients in these experiments. It may appear that unusual treatment, such as nursing patients on their backs, mainly in bed, and without any special treatment to prevent pressure sores, though it applied to all subjects in the trial, could give an unfair bias to results obtained on the experimental mattress. In fact in our initial experiments we attempted to use regular turning of patients at intervals of two to four hours as a control, but were soon obliged to abandon this, as, contrary to our expectations, it proved to be quite impracticable with the type of patient and staffing conditions in these wards. A study of the method of care actually in use convincei us that, despite frequent reference to it, turning was hardly ever practised and patients were nursed almost entirely lying on their backs. Apart from the regular

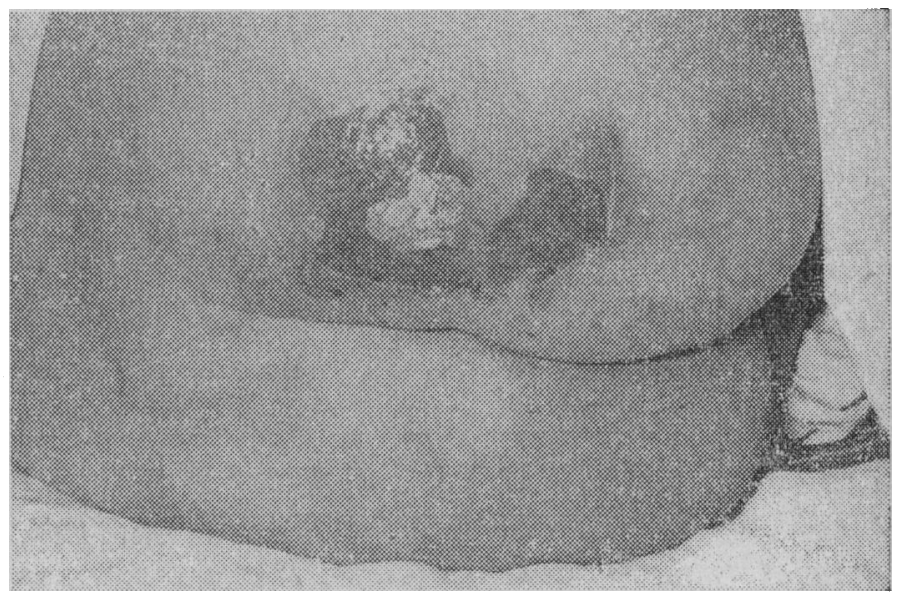

FIG. 2.--Superficial sore (grade ++ ).

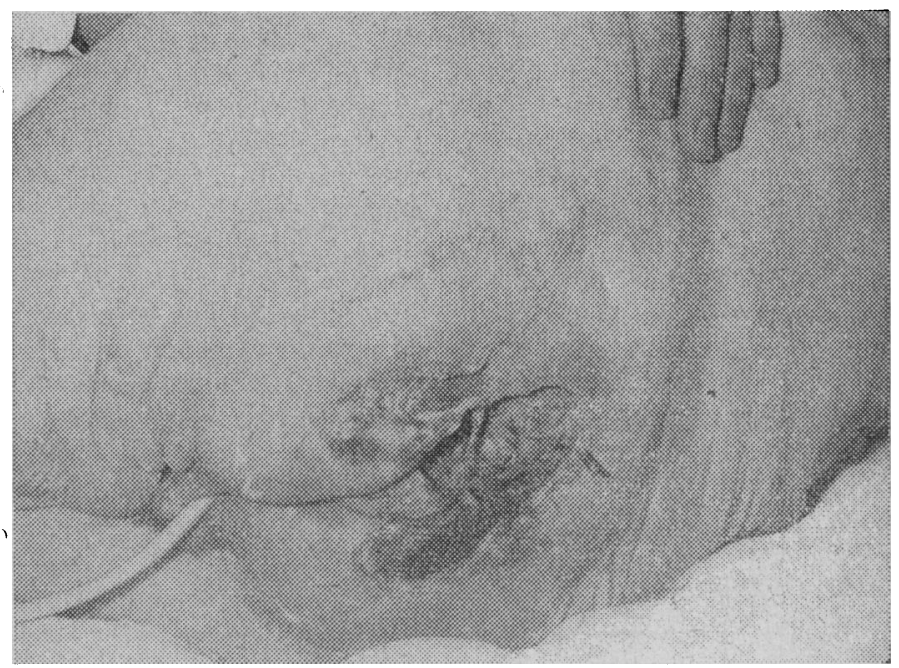

FIG. 3.-Gangrenous sore (grade $t+++$ ).

application of zinc cream to the pressure areas, the only difference between the usual ward care and that finally adopted for the control group was that, in the former, patients spent a great deal more time out of bed; at least half of even the ill patients were being sat out for from 4 to 10 hours daily.

We found no evidence that sitting patients out of bed reduced the incidence of pressure sores, and, particularly in ill patients, it often increased their discomfort and distress. For this reason, and so that patients in the trial should spend a more or less standard amount of time in bed-that is, in a position to receive such benefit as the experimental mattress being tested could supply-we limited the time subjects were allowed to be up to four hours daily. Admitting this difference, we do not think that the system of nursing used, which constituted the only special form of management of patients on the control treatment, was so far removed from normal practice in these wards as to be artificial. In fact our studies showed that the incidence 
of pressure sores in the control group and that in similar patients nursed on normal ward care were very much the same.

\section{Results}

Eighty-three patients were entered for trials on the largecelled ripple bed and the control treatment. Table II shows the numbers entered with and without sores, the sex, type (whether new patient or inpatient), mean ages, and mean clinical scores of patients in each group. There is a disparity in the sex ratios which is difficult to understand, but this should not affect the results, as no difference has ever been demonstrated between the incidence or course of pressure sores between males and females. Ten patients-four on the ripple bed and six in the control group-died before their second assessment, and three trials of the ripple bed had to be abandoned because of breakdowns in the machines, so that the progress of only 70 patients was finally available for analysis.

\begin{tabular}{|c|c|c|c|c|c|c|c|c|c|}
\hline \multirow[b]{2}{*}{ Bed } & \multirow{2}{*}{$\begin{array}{c}\text { Total } \\
\text { No. } \\
\text { of } \\
\text { Patients } \\
\text { Entered }\end{array}$} & \multicolumn{2}{|c|}{$\begin{array}{c}\text { Sores on } \\
\text { Entry }\end{array}$} & \multicolumn{2}{|c|}{ Sex } & \multicolumn{2}{|c|}{ Type } & \multirow{2}{*}{$\underset{\text { Age }}{\text { Mean }}$} & \multirow{2}{*}{$\begin{array}{l}\text { Mean } \\
\text { Clin- } \\
\text { ical } \\
\text { Score } \\
\text { on } \\
\text { Entry }\end{array}$} \\
\hline & & $\begin{array}{l}\text { No } \\
\text { Trunk } \\
\text { Sores }\end{array}$ & $\begin{array}{l}\text { Super- } \\
\text { ficial } \\
\text { Trunk } \\
\text { Sores }\end{array}$ & $\mathbf{M}$ & $\mathrm{F}$ & Pew & $\begin{array}{c}\text { In- } \\
\text { patient }\end{array}$ & & \\
\hline $\begin{array}{l}\text { Large-celled } \\
\text { ripple bed } \\
\text { Control }\end{array}$ & $\begin{array}{l}42 \\
41\end{array}$ & $\begin{array}{l}19 \\
21\end{array}$ & $\begin{array}{l}23 \\
20\end{array}$ & $\begin{array}{l}10 \\
17\end{array}$ & $\begin{array}{l}32 \\
24\end{array}$ & $\begin{array}{l}9 \\
6\end{array}$ & $\begin{array}{l}33 \\
35\end{array}$ & $\begin{array}{l}80 \cdot 4 \\
82 \cdot 1\end{array}$ & $\begin{array}{l}10.5 \\
10.5\end{array}$ \\
\hline All & 83 & 40 & 43 & 27 & 56 & 15 & 68 & $81 \cdot 2$ & 10.5 \\
\hline
\end{tabular}

Fig. 4 shows in a simple pictorial fashion the results obtained. The vertical axes represent sores in grades of severity $0-+++$, at which point, in sores of the trunk, a patient's trial was stopped. The abscissae represent the 0-14 days of the trial and the follow-up. The graphs of patients who died during the trial, or who were discharged on account of clinical improvement (it was not considered justifiable to continue to nurse a patient under the conditions of the trial if his clinical score had fallen below 7), have been terminated with " $D$ " or "I" respectively; trials which had to be stopped on account of patients developing severe sores are shown with an "S." The results of patients who did and those who did not have trunk sores on admission have been shown separately, and the progress of the heels for the two groups combined (excluding those who had gangrenous heel sores on entry) are given underneath.

\section{Trunk Sores}

Fifteen patients without trunk sores on entry to the trial were nursed on the large-celled ripple bed and 18 on the control regimen. Only one of the patients. on the ripple bed developed a sore of severity grade ++ ; two others developed sores of grade + ; and the rest remained without sores during the period of the trial. In the control group 7 out of 18 patients developed sores of grade +++ or more, so that their trials had to be stopped. In patients entering the trial with existing sores, of the 20 nursed on the large-celled ripple bed all showed more or less rapid improvement in their pressure areas, as denoted by the upward slope of the tracings. In the control group 10 out of 17 patients developed severe sores.

In the follow-up assessments it can be seen that 9 out of the total of 17 patients who were examined two days after removal from the large-celled ripple bed showed a sudden deterioration in their pressure areas; five of them had developed gangrenous sores in this time. Only 3 out of the 12 patients who reached the 16th day in the control group had become worse, presumably because the majority of the most susceptible of these patients had already been removed from the trial because of the development of severe sores.

\section{Heel Sores}

Two patients nursed on the large-celled ripple bed developed minimal patches of discoloration on one heel ; one of these patches was evidently due to pressure of the inside of the heel against the opposite knee in a woman with severe contractures. Thirteen of the 30 patients in the control group developed sores of the heels, and in 7 out of the 13 one or both heels became gangrenous.

\section{Discussion}

Contrasted with its control the large-celled ripple bed appeared effective in preventing and healing pressure sores. The small-celled ripple bed, which was also tested in these trials, and the results of which have been described (Bliss et al., 1966), seemed to be nearly as effective in preventing and healing sores of the trunk, but was less efficient in preventing heel sores. In addition, it was noticed that patients with marked bony prominences, or patients (not in these trials) being nursed on their sides on the small-celled mattress, often developed severe sores over the sacrum or greater trochanters. The largecelled mattress appeared to afford protection to patients in whatever position they might be lyingfor example, as a separate experiment, one very ill woman with multiple pressure sores was nursed for three weeks, until her death, lying on her left hip on a large-celled ripple bed without developing a sore.

It will not, however, be sufficient simply to state that an effective method of preventing pressure sores exists. Many doctors and nurses adopt a defeatist attitude towards bed sores, arising from an (in our opinion erroneous) impression that they are an inevitable accompaniment of terminal illness, that they are painless, and that they have little effect on the course of the patient's illness. In fact, as has been shown, at least one-third of pressure sores occurring in geriatric patients are not associated with terminal illness, and even in those patients who die the duration of sores before death is usually long enough for them to be a cause of concern to the ward staff and distress to the patient.

In these studies it was found that pressure sores were often very painful, especially superficial sores and sores of the heels. Recovery of sores with treatment was associated not only with improvement in the patient's sense of well-being, but often with an Fig. 4. - Progress of pressure areas on (1) large-celled ripple bed, and (2) control
regimen. $D=$ died. $I=$ improved. $S=$ trial stopped. 
apparently real improvement in his general condition also. On the other hand, patients who developed gangrenous sores of the trunk or heels during a short illness, from which they quickly recovered, often had to remain in hospital for many months because of unhealed sores. Besides the effect on the patients, and even apart from the time taken up by complicated and unpleasant dressings, the presence of many patients with large gangrenous sores has a depressing effect on ward morale. The finding of an effective technique for preventing pressure sores, and training in its use, could be the first step towards a more positive approach to this problem, enabling medical and nursing staff to collaborate in the management of a patient's pressure areas as rationally as is done in other aspects of his care-for example, in the management of postoperative complications.

Early recognition of patients at risk is essential in any method of preventing pressure sores. Patients are usually placed on prophylactic regimens too late, often after severe sores have already occurred. Though we have shown that the large-celled ripple bed does appear to allow superficial sores to heal and to prevent deeper damage, it can be of only limited benefit in patients with full-thickness skin loss. We found that the scoring system used in these trials was very successful in identifying susceptible subjects, and that few pressure sores occurred in patients with scores under 7. The habit of constantly reappraising patients under the headings of the score quickly trained users to become automatically alert to warning signs in their condition, often without actually evaluating the figures. Such a system might be useful in training medical students and nurses to recognize patients at risk and in giving them confidence in applying preventive techniques.

At present there are several difficulties associated with alternating pressure mattresses, some of which are due to lack of training in their use and others to deficiencies in the machines themselves. Besides being placed on these mattresses too late, it was often found that patients were nursed with pillows or pads between them and the mattress, or with a mattress improperly positioned in the bed, or in which the tubes had become kinked or detached during bedmaking. Motors are sometimes switched off or left disconnected after beds have been moved-for example, during ward cleaning. In addition, ward staff do not always appear to appreciate when mattresses have developed faults. Breakdowns are occasionally due to failure of the motors, but more often to leaks developing in the mattress. Besides direct splits, usually by the side of seam welds, leaks can also occur between adjacent cells, so that the two series are brought into communication; these leaks are particularly difficult to detect by inspection, and they do not trigger off the warning light on the motor. (Warning systems on these machines need to be very precise and reliable.) Even the smallest pinhole in a mattress destroys its alternating action. In some very ill patients merely a few hours spent on a defective mattress may be sufficient to cause severe sores.

Though the unreliability of these mattresses has hitherto been a serious disadvantage, we feel that this should not be allowed to discourage their use, or the search for more robust apparatus. Of all the methods of preventing pressure sores which were tested in these trials alternating pressure mattresses proved to be the most effective and practical. Their disadvantages must be weighed against those of other advocated techniques-for example, regular turning, which is often impracticable in wards where there are large numbers of susceptible patients, and inadequate nursing skills available, especially at night.

\section{Summary}

This report is a description of a trial of nursing 42 geriatric patients, who were estimated to be liable to develop pressure sores, on a new type of alternating pressure mattress, the largecelled ripple bed, compared with a control group of 41 similar patients nursed on ordinary hospital mattresses. Each patient was nursed in the trial for 14 days under standard nursing care, and a record kept of his clinical progress and the condition of his pressure areas.

Compared with the results of the control group, the largecelled ripple bed appeared effective in preventing and healing pressure sores of the trunk and heels. The advantages and disadvantages of this method of treating patients are discussed.

We are deeply indebted to the North-west Metropolitan Regional Hospital Board for a generous grant which enabled us to carry out these studies. We also acknowledge the help given by Messrs. Talley Surgical Instruments Ltd., London N.7, in developing the largecelled ripple mattress.

\section{REFERENCES}

Bliss, M. R. (1964). Geront. Clin. (Basel), 6, 10

McLaren, R., and Exton-Smith, A. N. (1966). M. Bull. Min. Health, 25, 238

Blockey, N. J. (1953). Lancet, 2, 21.

Ewing, M. R., Garrow, C., and McHugh, N. (1961). Ibid., 2, 1447 Exton-Smith, A. N. (1966). In Medicine in Old Age, edited by J. N. Agate, London.

Gardner; W. J., Anderson, R. M., and Lyden, M. (1954). Arch. phys. Med., 35 , 578 .

Hofman, H. M., McLaughlin, E., Gilpatrick, M., Breeze, E., and Webb, M. (1949). Amer. ₹. Nurs., 49, 654.

Norton, D., McLaren, R., and Exton-Smith, A. N. (1962). An Investigation of Geriatric Nursing Problems in Hospital. National Corporation for the Care of Old People, London.

Sandock, L. F. (1962). F. Indian med. Ass., 55, 344 